\title{
Electrocardiogram for the Diagnosis of Right Ventricular Hypertrophy and Dilation in Idiopathic Pulmonary Arterial Hypertension
}

\author{
Grzegorz Kopeć, MD, PhD; Anna Tyrka, MD; Tomasz Miszalski-Jamka, MD, PhD; \\ Maciej Sobień, MD; Marcin Waligóra, MD; Mateusz Brózda, MD; Piotr Podolec, MD, PhD
}

\begin{abstract}
Background: Currently, there are no data on the association between right ventricular (RV) structure and ECG changes specific for idiopathic pulmonary arterial hypertension (IPAH). Therefore, we aimed to assess the accuracy of the recommended ECG criteria for predicting RV hypertrophy $(\mathrm{RVH})$ and dilation in patients with IPAH.

Methods and Results: Twelve-lead ECG and cardiovascular magnetic resonance imaging (CMR) were performed in 23 consecutive patients with IPAH aged $49.8 \pm 16.3$ years. ECG criteria were referred to RV mass index and RV end-diastolic volume index as measured by CMR. Only the ECG voltage criteria based on R wave amplitude in lead $\mathrm{V} 1, \mathrm{R}$ wave amplitude in aVR, $\mathrm{P}$ wave amplitude in II and ventricular activation time in V1 were useful for differentiating between patients with and without $\mathrm{RVH}$. A ventricular activation time in lead $\mathrm{V} 1$ of $<0.01 \mathrm{~s}$ excluded $\mathrm{RVH}$, whereas $\mathrm{R}$ in V1 $>6 \mathrm{~mm}$, R:S in V1 $>1, \mathrm{R}$ in aVR $>4 \mathrm{~mm}$, R:S in V5 to R:S in V1<0.04 and P in II $>2.5 \mathrm{~mm}$ confirmed the diagnosis. Only the ventricular activation time in V1 correlated with RV dilation and when $>0.045$ s confirmed its diagnosis.
\end{abstract}

Conclusions: Only a few of the recommended ECG criteria proved to be useful in the diagnosis of RVH or RV dilation in patients with IPAH. Changes in the cut-off values improved their accuracy. (Circ $J$ 2012; 76: 1744-1749)

Key Words: Cardiovascular magnetic resonance imaging; ECG criteria; Idiopathic pulmonary arterial hypertension; Right ventricular mass; Right ventricular volume

$\mathbf{S}$ ustained pressure overload, secondary to chronic pulmonary hypertension, may lead to increase in right ventricular (RV) mass. As the disease progresses the RV dilates and eventually RV failure occurs. Increased RV volume but not mass has been recently shown to predict survival in patients with idiopathic pulmonary arterial hypertension (IPAH). ${ }^{1}$ However, the role of the RV mass as a risk predictor have been established in another subset of PAH patients. ${ }^{2}$ In those 2 studies cardiovascular magnetic resonance imaging (CMR) was used and this method is currently considered the gold standard ${ }^{3,4}$ for the assessment of structure and function of the RV. However, the high cost, low availability, and potential contraindications to CMR justify the interest in more commonly used and simpler tests to assess the increased RV mass and volume.

Current guidelines from the American Heart Association, the American College of Cardiology Foundation and the Heart Rhythm Society (AHA/ACCF/HRS) list 24 criteria for electrocardiographic (ECG) diagnosis of RV hypertrophy (RVH). ${ }^{5}$
They come from historical studies in inhomogeneous groups ${ }^{6,7}$ and currently there are no specific data on the association between RV structure and ECG changes in IPAH. Additionally, it is unknown to what extent the different criteria reflect the changes in RV mass and volume that can occur in IPAH. ${ }^{5}$

In the current study we aimed to assess prospectively how the available ECG criteria for RVH correlate with RV mass and volume as assessed by CMR and also to establish the best cut-off values of the ECG criteria in diagnosis of RVH (defined as an increase in mass) and dilation in patients with IPAH.

Methods
Patients
The consecutive patients with IPAH who remained under our
care between January 2009 and December 2010 were included
in this study. Patients were selected if they had pulmonary
hypertension confirmed in right heart catheterization; other

Received January 5, 2012; revised manuscript received February 23, 2012; accepted March 13, 2012; released online April 13 , 2012 Time for primary review: 24 days

Department of Cardiac and Vascular Diseases (G.K., A.T., M.S., M.W., M.B., P.P.), Center for Diagnosis, Prevention and Telemedicine (T.M.-J.), John Paul II Hospital, Kraków, Poland

Mailing address: Grzegorz Kopeć, MD, PhD, Department of Cardiac and Vascular Diseases John Paul II Hospital, Kraków, Poland. E-mail: gkopec@szpitaljp2.krakow.pl

ISSN-1346-9843 doi:10.1253/circj.CJ-11-1517

All rights are reserved to the Japanese Circulation Society. For permissions, please e-mail: cj@j-circ.or.jp 
etiologies of pulmonary hypertension were excluded based on the European Society of Cardiology guidelines ${ }^{8}$ and there were no contraindications to perform CMR examination. The study protocol conforms to the ethical guidelines of the 1975 Declaration of Helsinki and was approved by the institutional ethics committee. Informed consent was obtained from each patient before starting the study.

\section{Electrocardiography}

A 12-lead standard ECG $(10 \mathrm{~mm}=1 \mathrm{mV}, 50 \mathrm{~mm} / \mathrm{s})$ was acquired in a supine position during quiet respiration in the morning on the day of the CMR study and analyzed according to the current guidelines. For the purpose of the present study all 24 criteria for RVH recommended in AHA/ACCF/HRS guidelines $^{5}$ were assessed. Amplitude of $\mathrm{P}, \mathrm{R}$, and $\mathrm{S}$ waves and QRS duration were averaged from 3 consecutive cardiac cycles. The ECG interpreter was blinded to the results of the CMR study.

\section{Cardiovascular Magnetic Resonance Imaging}

Breath-hold, ECG-gated imaging was performed using cardiac-phased array coil on 1.5 T whole-body scanner (Magnetom Sonata Maestro Class, Siemens, Erlangen, Germany) in left and right ventricular short-axis and axial views. After scout imaging, cine imaging (steady-state free precision gradient echo technique; slice thickness $8 \mathrm{~mm}$, no gap, matrix $256 \times$ 192 , in-plane resolution $1.3 \times 1.3 \mathrm{~mm}^{2}$ ) was acquired.

Cine images were assessed off-line (MASS Medis, Leiden, the Netherlands) by independent, experienced observers blinded to other data. In the presence of discrepancy in qualitative assessment the consensus was reached.

Endocardial and epicardial borders were outlined on shortaxis images as previously described., ${ }^{9,10}$ If the basal slice contained both ventricular and atrial myocardium, contours were drawn up to their junction and joined by straight line through the blood pool. In the basal slice, if the pulmonary valve was visible, only the portion of volume surrounded by trabeculated myocardium below the pulmonary valve level was included. For the RV inflow portion, blood volume was excluded from the RV volume if the surrounding wall was thin and not trabeculated, as it was considered to be in the right atrium. Left and right ventricular end-diastolic volumes (EDV), end-systolic volumes, myocardial mass and ejection fractions (EF) were computed. EDV and myocardial mass were indexed to body surface area. The RV mass index (RVMI) and RVEDV index (RVEDVI) were expressed in $\mathrm{g} / \mathrm{m}^{2}$ and $\mathrm{ml} / \mathrm{m}^{2}$, respectively. RVMI to RVEDVI ratio was calculated. RVH and RV dilation were defined based on age and sex-specific mean +2 SD of RVMI and RVEDVI in healthy volunteers. ${ }^{4}$ For RVH it was $30 \mathrm{~g} / \mathrm{m}^{2}$ in men aged $<35$ years; $26 \mathrm{~g} / \mathrm{m}^{2}$ in men aged $\geq 35$ years; $27 \mathrm{~g} / \mathrm{m}^{2}$ in women aged $<35$ years and $25 \mathrm{~g} / \mathrm{m}^{2}$ in women aged $\geq 35$ years and for RV dilation $134 \mathrm{ml} / \mathrm{m}^{2}$ in men aged $<35$ years; $111 \mathrm{ml} / \mathrm{m}^{2}$ in men aged $\geq 35$ years; $111 \mathrm{ml} / \mathrm{m}^{2}$ in women aged $<35$ years and $118 \mathrm{ml} / \mathrm{m}^{2}$ in women aged $\geq 35$ years.

\section{Statistical Analysis}

Statistical analysis was performed with Statistica PL software (StatSoft, Inc [2001] STATISTICA [data analysis software system], Version 6.0, StatSoft, Inc, Tulsa, OK, USA) and Med-Calc ${ }^{\circledR}$ Version 8.1.1.0. Continuous variables are reported using means and standard deviations. Categorical variables are described as counts and percentages. Continuous variables were checked for normal distribution with chi-square test. The relationship between ECG criteria and RVMI, RVEDVI, as
Table 1. Characteristics of the Study Population and CMR Characterization of the Right Ventricle

n (\%)/mean \pm SD

\begin{tabular}{lc} 
Age [years] & $49.8 \pm 16.3$ \\
BSA [m²] & $1.7 \pm 0.2$ \\
Male & $10(43 \%)$ \\
Time from diagnosis of IPAH [month] & $23.7 \pm 54.0$ \\
NYHA & \\
$\quad$ I & 0 \\
II & $9(39 \%)$ \\
III & $12(52 \%)$ \\
IV & $2(9 \%)$ \\
RVM [g] & $62.1 \pm 40.4$ \\
RVMI [g/m²] & $34.9 \pm 201$ \\
RVH present [n] & $16(70 \%)$ \\
RVEDV [ml] & $208.8 \pm 95.1$ \\
RVEDVI [ml/m²] & $114.3 \pm 48.0$ \\
RVEF [\%] & $35.2 \pm 14.8$ \\
\hline
\end{tabular}

CMR, cardiac magnetic resonance imaging; BSA, body surface area; IPAH, idiopathic pulmonary arterial hypertension; RVM, right ventricular (RV) mass; RVMI, RV mass index; RVH, RV hypertrophy; RVEDV, RV end-diastolic volume; RVEDVI, RV end-diastolic volume index; RVEF, RV ejection fraction.

\begin{tabular}{|c|c|}
\hline ECG criteria and cut-off values & $\begin{array}{l}\text { Frequency } \\
\quad(\%)\end{array}$ \\
\hline $\mathrm{R}$ in $\mathrm{V} 1(\mathrm{Rv} 1)>6 \mathrm{~mm}$ & 35 \\
\hline $\mathrm{R}: \mathrm{S}$ ratio in $\mathrm{V} 1\left(\mathrm{R}: \mathrm{S}_{\mathrm{v} 1}\right)>1$ & 67 \\
\hline$S$ in V5 (Sv5) $>10 \mathrm{~mm}$ & 26 \\
\hline $\mathrm{S}$ in $\mathrm{V} 6\left(\mathrm{~Sv}_{6}\right)>3 \mathrm{~mm}$ & 74 \\
\hline$R$ in aVR $(\operatorname{RavR})>4 \mathrm{~mm}$ & 17 \\
\hline $\mathrm{S}$ in $\mathrm{V} 1\left(\mathrm{~S}_{\mathrm{V} 1}\right)<2 \mathrm{~mm}$ & 61 \\
\hline $\mathrm{R}$ in $\mathrm{V} 5$ or $\mathrm{V} 6\left(\mathrm{R}_{\mathrm{v} 5,6}\right)<3 \mathrm{~mm}$ & 8.7 \\
\hline $\mathrm{R}: \mathrm{S}$ ratio in V5 (R:Sv5) $<0.75$ & 39 \\
\hline $\mathrm{R}: \mathrm{S}$ ratio in $\mathrm{V} 6(\mathrm{R}: \mathrm{S} v 6)<0.4$ & 4 \\
\hline$R: S$ in V5 to R:S in V1 ratio (R:Sv5 to R:Sv1) $<0.04$ & 6.7 \\
\hline$R_{I}+S_{I I I}-\left(S_{I}+R_{I I I}\right)<15 \mathrm{~mm}$ & 96 \\
\hline $\begin{array}{l}\text { Max. } \mathrm{R} \text { in } \mathrm{V} 1 \text { or } \mathrm{V} 2+\max . \mathrm{S} \text { in } \mathrm{I} \text { or aVL-S in } \mathrm{V} 1 \\
\left(\operatorname{maxR} \mathrm{V}_{1,2}+\max \mathrm{S}_{\mathrm{l}, \mathrm{aV}}-\mathrm{S}_{\mathrm{V} 1}\right)>6 \mathrm{~mm}\end{array}$ & 83 \\
\hline$R$ in $V_{1}+S$ in $V_{5}$ or $V_{6}\left(R_{v 1}+S_{v 5,6}\right)>10.5 m m$ & 74 \\
\hline $\begin{array}{l}\text { Ventricular activation time in } \mathrm{V} 1>0.035 \mathrm{~s} \text { with QRS } \\
<0.12 \mathrm{~s}\end{array}$ & 75 \\
\hline P amplitude in II $\left(P_{\|}\right)>2.5 \mathrm{~mm}$ & 26 \\
\hline Presence of QR in V1 (QRv1) & 61 \\
\hline RSR in V1 with QRS $>0.12 s\left(R_{\left.S R v_{1}\right)}>120 \mathrm{~ms}\right.$ & 0 \\
\hline $\mathrm{S}>\mathrm{R}$ in $\mathrm{I}$ & 78 \\
\hline $\mathrm{S}>\mathrm{R}$ in II & 22 \\
\hline$S>R$ in III & 8.7 \\
\hline$S$ in I and $Q$ in III (S।QıI) & 78 \\
\hline$R: S$ in $V 1>R: S$ in $V 3$ & 67 \\
\hline$R: S$ in $V 1>R: S$ in V4 & 67 \\
\hline Negative $\mathrm{T}$ wave in $\mathrm{V} 1$ through $\mathrm{V} 3$ & 57 \\
\hline
\end{tabular}

$\mathrm{RVH}$, right ventricular hypertrophy. 


\begin{tabular}{|c|c|c|c|c|}
\hline \multirow{2}{*}{ Criterion } & \multicolumn{2}{|c|}{ RVMI } & \multicolumn{2}{|c|}{ RVEDVI } \\
\hline & $r$ & $P$ value & $r$ & $P$ value \\
\hline $\mathrm{R}_{\mathrm{v} 1}$ & 0.71 & 0.0001 & 0.19 & 0.39 \\
\hline $\mathrm{R}: \mathrm{Sv}_{1}$ & 0.67 & 0.006 & 0.09 & 0.74 \\
\hline Sv5 & 0.21 & 0.33 & -0.1 & 0.63 \\
\hline Sv6 & 0.22 & 0.31 & 0.05 & 0.84 \\
\hline Ravr & 0.45 & 0.03 & 0.15 & 0.48 \\
\hline $\mathrm{Sv}_{1}$ & -0.1 & 0.78 & -0.14 & 0.53 \\
\hline Rv5,6 & 0.17 & 0.43 & -0.31 & 0.15 \\
\hline $\mathrm{R}: \mathrm{Sv}_{5}$ & -0.1 & 0.83 & -0.29 & 0.19 \\
\hline $\mathrm{R}: \mathrm{Sv}_{6}$ & 0.02 & 0.93 & -0.16 & 0.47 \\
\hline$R: S_{v 5}$ to $R: S_{v 1}$ & -0.72 & 0.003 & -0.21 & 0.46 \\
\hline$\left(R_{I}+S_{I I I}\right)-\left(S_{I}+R_{I I I}\right)$ & -0.38 & 0.07 & 0.25 & 0.24 \\
\hline $\max \mathrm{Rv}_{1,2}+\max \mathrm{Sl}_{1, \mathrm{avL}}-\mathrm{S}_{\mathrm{v} 1}$ & 0.59 & 0.003 & 0.02 & 0.93 \\
\hline $\mathrm{R}_{\mathrm{v} 1}+\mathrm{S}_{\mathrm{v} 5,6}$ & 0.54 & 0.008 & 0.05 & 0.82 \\
\hline Ventricular activation time $\mathrm{V} 1$ & 0.54 & 0.01 & 0.64 & 0.002 \\
\hline$P_{\|}$ & 0.52 & 0.01 & 0.12 & 0.59 \\
\hline
\end{tabular}

RVMI, right ventricular (RV) mass index; RVEDVI, RV end-diastolic volume index; MRI, magnetic resonance imaging.

well as the RVMI to RVEDVI ratio, was estimated by Pearson or Spearman correlation tests for continuous variables and by the chi-square test for categorical variables with Yates correction if appropriate. When a correlation was significant for the whole group we additionally calculated correlation coefficients separately in men and women and then compared them with the use of Fisher's Z transformation. Receiver-operating characteristics analysis was performed to calculate the area under the curve (AUC), which describes accuracy of a test to discriminate diseased cases from normal cases. RVH or RV dilation as assessed by CMR were the reference standards against which the AUC of recommended ECG criteria were assessed. For criteria with significant discriminative capacity we calculated sensitivity, specificity, positive predictive values, and negative predictive values of the currently recommended cut-off values. Additionally, the cut-off values with the highest sensitivity and specificity were established for these criteria. The significance level was set at $\mathrm{P}<0.05$.

\section{Results}

\section{Patients}

The clinical characteristics of the study population with CMR characterization of the RV are summarized in Table 1 . Of 26 patients with IPAH, 2 had claustrophobia and 1 had a hip prosthesis, which excluded them from the CMR study. Finally, we enrolled 23 patients (10 men) with a mean age of $49.8 \pm 16.3$ years. Among them, 13 patients were diagnosed de novo and did not take PAH-specific drugs. The other 10 patients were diagnosed for IPAH before and were taking a calcium-channel blocker ( 4 patients; in 3 patients the calciumchannel blocker was further changed to $\mathrm{PAH}$-specific drug after an acute vasoreactivity test), sitaxentan (1 patient), sildenafil (1 patient), iloprost (1 patient), a combination of iloprost, sildenafil and sitaxentan (1 patient), a combination of treprositnil, sildenafil and sitaxentan (1 patient) and treprostinil with sildenafil (1 patient). All patients were in sinus rhythm with an average heart rate of $78.4 \pm 16.4$ beats $/ \mathrm{min}$. Mean electrical heart axis was $78.6 \pm 75.8$ degrees; 4 patients had a normal axis, 16 had right axis deviation, 1 had left axis deviation and
2 had indeterminate axis deviation. No patient fulfilled the criteria for right bundle branch block; 1 patient had left bundle branch block and 2 patients had nonspecific intraventricular conduction abnormalities. As assessed by CMR, the left ventricular EF was $58.9 \pm 9.5 \%$ and left ventricular hypertrophy was found in $4(17 \%)$ patients. RVH was found in $16(70 \%)$ patients and RV dilation in $9(39 \%)$ patients. RV dilation was present only in patients with RVH. There was a significant correlation between RVMI and RVEDVI ( $\mathrm{r}=0.43$; $\mathrm{P}=0.04)$.

\section{Prevalence of RVH Based on Currently Recommended ECG Criteria}

All ECG criteria were calculated in 23 patients, apart from R: $\mathrm{Sv}_{\mathrm{v}}, \mathrm{R}: \mathrm{Sv}_{\mathrm{v}}>\mathrm{R}: \mathrm{Sv}_{\mathrm{v}}, \mathrm{R}: \mathrm{Sv}_{\mathrm{v}}>\mathrm{R}: \mathrm{Sv}_{\mathrm{v}}$, and R:Sv5 to R:Sv1, which were calculated in 15 patients because no $S$ wave was present in lead V1 of 8 ECGs. Ventricular activation time in V1 was calculated for 20 patients because in the 3 other patients there was no R wave in V1. The prevalence of RVH based on the recommended ECG cut-off values varied markedly across the analyzed criteria, ranging from 0 to 22 as presented in Table 2.

\section{Relationship Between ECG Criteria and RV Mass and Volume}

The following ECG criteria correlated significantly with the RVMI: Rv1, R:Sv1, RavR, R:Sv5 to R:Sv1, maxRv1,2 + maxSI,avL$\mathrm{Sv}_{\mathrm{v} 1}, \mathrm{Rv}_{1}+\mathrm{SV}_{\mathrm{v}, 6}$, ventricular activation time in $\mathrm{V} 1$ and $\mathrm{P}$ wave amplitude in II. Only the ventricular activation time in lead V1 correlated with RVEDVI (Table 3). Additionally, R:Sv1 $>\mathrm{R}$ : $\mathrm{Sv}_{3}$ and the R:Sv1 $>\mathrm{R}: \mathrm{S}_{4} 4$ was more frequent in patients with than in those without $\mathrm{RVH}$ ( 8 vs. $0, \mathrm{P}=0.03$ ). No correlation was found between assessed ECG criteria and the RVMI to RVEDVI ratio. The calculated correlation coefficients were similar in male and female groups.

Accuracy of ECG Criteria in Predicting RVH and RV Dilation Only 10 of the 24 ECG criteria were able to discriminate between patients with and without RVH (Table 4) and there was no significant difference in the AUC of these criteria. Sensitivity, specificity, positive and negative predictive values of the 


\begin{tabular}{|c|c|c|c|}
\hline Criteria & AUC & $95 \% \mathrm{Cl}$ & $P$ value \\
\hline $\mathrm{Rv}_{1}>6 \mathrm{~mm}$ & 0.87 & $0.66-0.97$ & $<0.0001$ \\
\hline $\mathrm{R}: \mathrm{S}_{\mathrm{v} 1}>1$ & 0.91 & $0.65-0.99$ & $<0.0001$ \\
\hline Sv5 $>10 \mathrm{~mm}$ & 0.58 & $0.36-0.78$ & 0.64 \\
\hline $\mathrm{S}_{\mathrm{v} 6}>3 \mathrm{~mm}$ & 0.52 & $0.30-0.73$ & 0.92 \\
\hline Ravr $>4 \mathrm{~mm}$ & 0.74 & $0.52-0.90$ & 0.03 \\
\hline $\mathrm{S}_{\mathrm{v} 1}<2 \mathrm{~mm}$ & 0.52 & $0.30-0.73$ & 0.91 \\
\hline $\mathrm{Rv}_{\mathrm{v}, 6}<3 \mathrm{~mm}$ & 0.59 & $0.37-0.79$ & 0.59 \\
\hline $\mathrm{R}: \mathrm{Sv}_{5}<0.75$ & 0.55 & $0.33-0.75$ & 0.79 \\
\hline$R: S_{v}<0.4$ & 0.60 & $0.37-0.80$ & 0.58 \\
\hline $\mathrm{R}: \mathrm{Sv}_{5}$ to $\mathrm{R}: \mathrm{Sv}_{1}<0.04$ & 0.91 & $0.65-0.99$ & $<0.0001$ \\
\hline$\left(R_{I}+S_{I I I}\right)-\left(S_{I}+R_{I I I}\right)<15 \mathrm{~mm}$ & 0.64 & $0.41-0.83$ & 0.29 \\
\hline $\max \mathrm{Rv}_{1,2}+\max \mathrm{Sl}_{1, \mathrm{avL}}-\mathrm{Sv}_{1}>6 \mathrm{~mm}$ & 0.80 & $0.58-0.94$ & 0.01 \\
\hline $\mathrm{Rv}_{\mathrm{v} 1}+\mathrm{S}_{\mathrm{v} 5,6}>10.5 \mathrm{~mm}$ & 0.78 & $0.56-0.92$ & 0.03 \\
\hline Ventricular activation time $\mathrm{V} 1>0.035 \mathrm{~s}$ & 0.83 & $0.60-0.96$ & 0.004 \\
\hline QRv1 present & 0.63 & $0.41-0.82$ & 0.27 \\
\hline RSRv1 present (>0.12s) & - & - & - \\
\hline S>R in I present & 0.55 & $0.33-0.76$ & 0.64 \\
\hline S>R in II present & 0.55 & $0.33-0.76$ & 0.55 \\
\hline S>R in III present & 0.54 & $0.32-0.75$ & 0.61 \\
\hline S। and Q QII present & 0.65 & $0.42-0.84$ & 0.18 \\
\hline$R: S_{1}>R: S_{3}$ present & 0.78 & $0.51-0.95$ & 0.04 \\
\hline $\mathrm{R}: \mathrm{Sv}_{1}>\mathrm{R}: \mathrm{S}_{4} 4$ present & 0.78 & $0.51-0.95$ & 0.04 \\
\hline Negative $T$ wave in $V_{1}$ through $V_{3}$ present & 0.60 & $0.38-0.79$ & 0.41 \\
\hline$P_{\|}>2.5 \mathrm{~mm}$ & 0.84 & $0.62-0.96$ & 0.0001 \\
\hline
\end{tabular}

$\mathrm{RVH}$, right ventricular hypertrophy; IPAH, idiopathic pulmonary arterial hypertension; AUC, area under curve; $\mathrm{Cl}$, confidence interval.

\begin{tabular}{|c|c|c|c|c|c|c|c|c|c|c|}
\hline & $\begin{array}{l}\text { Current } \\
\text { cut-off }\end{array}$ & SE & SP & PPV & NPV & $\begin{array}{c}\text { Best } \\
\text { cut-off }\end{array}$ & SE & SP & PPV & NPV \\
\hline $\mathrm{Rv}_{1}$ & $>6 \mathrm{~mm}$ & 50 & 100 & 100 & 47 & $>3 \mathrm{~mm}$ & 94 & 71 & 88 & 83 \\
\hline $\mathrm{R}: \mathrm{Sv}_{1}$ & $>1$ & 90 & 100 & 100 & 80 & $>1$ & 90 & 100 & 100 & 80 \\
\hline Ravr & $>4 \mathrm{~mm}$ & 25 & 100 & 100 & 37 & $>2 \mathrm{~mm}$ & 68 & 71 & 85 & 50 \\
\hline $\mathrm{R}: \mathrm{S}_{\mathrm{v}}$ to $\mathrm{R}: \mathrm{S}_{\mathrm{v}}$ & $<0.04$ & 18 & 100 & 100 & 31 & $<0.4$ & 72 & 100 & 100 & 57 \\
\hline $\max R_{v_{1}, 2}+\max S_{1, a v L}-S_{v 1}$ & $>6 \mathrm{~mm}$ & 93 & 50 & 81 & 75 & $>10 \mathrm{~mm}$ & 75 & 85 & 96 & 60 \\
\hline $\mathrm{R}_{\mathrm{v} 1}+\mathrm{Sv}_{5,6}$ & $>10.5 \mathrm{~mm}$ & 81 & 57 & 81 & 57 & $>13 \mathrm{~mm}$ & 69 & 85 & 92 & 54 \\
\hline R peak V1 & $>0.035 \mathrm{~s}$ & 42 & 83 & 86 & 36 & $>0.01 \mathrm{~s}$ & 100 & 67 & 88 & 100 \\
\hline$P_{\| I}$ & $>2.5 \mathrm{~mm}$ & 19 & 100 & 100 & 35 & $>1.5 \mathrm{~mm}$ & 69 & 100 & 100 & 58 \\
\hline
\end{tabular}

PPV, positive predictive value; NPV, negative predictive value; RVH, right ventricular hypertrophy; SE, sensitivity; $\mathrm{SP}$, specificity.

currently recommended and the best (with highest specificity and sensitivity) cut-off values of these ECG criteria for RVH are presented in Table 5.

Only ventricular activation time in lead V1 discriminated well between patients with and without $\mathrm{RV}$ dilation ( $\mathrm{AUC}=0.77$; $\mathrm{P}=0.02$ ). For the cut-off value of $0.035 \mathrm{~s}$ the sensitivity was $62 \%$, specificity $83 \%$, positive predictive value $71 \%$ and negative predictive value $77 \%$. The best cut-off value of $\mathrm{R}$ peak V1 was $0.045 \mathrm{~s}$ and it predicted RV dilation with a sensitivity of $50 \%$ and specificity of $100 \%$.

\section{Discussion}

In the present study, we demonstrated that in patients with IPAH only the criteria based on the $\mathrm{R}$ wave amplitude in
ECG lead V1 (Rv1 >6mm, R:Sv1 >1, R:Sv5 to R:Sv1 <0.04, $\operatorname{maxRv1,2}+\operatorname{maxSI}_{\mathrm{I}, \mathrm{avL}}-\mathrm{Sv}_{1}>6 \mathrm{~mm},\left(\mathrm{Rv}_{1}+\mathrm{Sv}_{5,6}\right)>10.5 \mathrm{~mm}, \mathrm{R}$ : $\left.\mathrm{S}_{\mathrm{V} 1}>\mathrm{R}: \mathrm{S}_{\mathrm{V} 3}, \mathrm{R}: \mathrm{S}_{\mathrm{V} 1}>\mathrm{R}: \mathrm{S}_{\mathrm{V} 4}\right), \mathrm{R}$ wave amplitude in aVR, $\mathrm{P}$ wave amplitude in II and the ventricular activation time in V1 were useful for predicting RVH. We have also specified the cut-off values of these criteria that differentiated between patients with and without RVH with the greatest accuracy. Most of the cut-off values differed from the currently recommended ones. Another finding from our study is that the ventricular activation time in V1 was the only ECG marker of RV dilation in IPAH patients.

Investigation into markers of increased RV mass or volume can be justified by recent publications in which CMR was used for the assessment of RV structure. Wolferen et al have demonstrated that increased RV EDV, as well as progressive 
$\mathrm{RV}$ dilation during treatment, are predictors of poor survival in IPAH patients, ${ }^{1}$ in contrast with RV mass, which did not predict mortality in this group of patients. However, the prognostic role of RV mass in pulmonary hypertension can not be neglected because it was shown in another work that in patients with systemic sclerosis, of whom $70 \%$ had PAH, RV mass as expressed by the ventricular mass index predicted survival in 1- and 2-year follow-up. ${ }^{2}$ CMR used in those studies is now considered the gold standard method for the characterization of the anatomy, function and mass of the $\mathrm{RV}^{3,4}$ and additionally, its role in determining pulmonary artery distensibility has been shown recently. ${ }^{11}$ Good correlation between autopsy data and RV mass measured by CMR was previously described in an animal model. ${ }^{12}$ In human studies the reproducibility of the measurement of RV volume, function, and mass with CMR has been shown. ${ }^{13}$ However, claustrophobia or metal body devices make this method inapplicable in some patients and also, some patients are not able to stop breathing for the required amount of time to get precise images. These limitations led to a $10 \%$ exclusion rate in the current study, which confirms the need for simpler and more available tests to investigate RVH or RV dilation. Recently, the role of ECG in the diagnosis of pulmonary hypertension, an issue neglected for many years, has been redefined. ${ }^{14-16}$

Although there are now as many as 24 recommended ECG criteria for RVH, their association with RV mass or volume specifically in patients with IPAH has not been evaluated. Additionally, these criteria have not been referred to RV mass and volume as measured by CMR in any group of pulmonary hypertension patients. Currently recommended ECG criteria for RVH are based on 2 types of studies. In the first type, no direct measurements of RV mass or volume were made and the diagnosis of RVH was based on an assumption of this abnormality, based on a clinical diagnosis of a condition associated with increased workload on the RV.${ }^{17-19}$ In the second type of study, RV mass was measured postmortem, which was associated with a not well-defined time delay between the mass measurement and ECG performance. An additional limitation of these postmortem studies was a lack of a clear anatomic definition of RVH. ${ }^{20}$ These limitations were overcome in our present study in which the ECG and RV mass were measured on the same day. Additionally, in order to assess the accuracy of different ECG criteria in the diagnosis of $\mathrm{RVH}$ or dilation we used clearly defined cut-off values based on CMR studies made in healthy subjects.

Although the term "criteria for ventricular hypertrophy" used in the AHA/ACCF/HRS guidelines suggests that increased mass of a ventricle is the main determinant of the ECG changes, there is no consensus to what extent increased mass or volume of a ventricle influences different ECG patterns. In the work done by Antman et al, increased volume of the left ventricle rather than thickened myocardium played a greater role in augmentation of the ECG voltage. ${ }^{21}$ In contrast, Devereux et al found that ECG voltage criteria are independent of left ventricular chamber dilatation. ${ }^{22}$ To date, the results of such analysis for the RV has not been available. Data from our study suggest a dominant role of $\mathrm{RVH}$, but not dilation, in determining the ECG voltage criteria. The lack of correlation between ECG parameters and the RVMI to RVEDVI ratio further underscores the effect of the absolute value of RV mass on these ECG criteria.

Because V1 is the closest lead to the RV it is not surprising that ECG voltage criteria based on R in V1 correlate best with RVH. From the non-voltage criteria, only the ventricular activation time, which represents the interval from the onset of ventricular depolarization to the time that the activation wavefront reaches the area under the electrode, correlated with RV mass as well as RV volume. Negative T waves from V1 to V3 did not appear more frequently in patients with RVH or dilation. Such repolarization abnormalities in the left ventricle have been suggested to correlate with impaired early relaxation, which may not necessarily be related to ventricular cavity dimension or to the presence of increased mass alone. ${ }^{23}$

Most of the recommended cut-off values for the ECG criteria for RVH have high positive and low negative predictive value, which means that a significant proportion of patients with RVH will be underdiagnosed using the ECG criteria and this supports findings from previous studies. ${ }^{5}$ Changing most of the cut-off values caused an increase in their sensitivity without significant change in specificity. The most sensitive criterion for RVH was the ventricular activation time in V1, which at the cut-off value of $0.01 \mathrm{~s}$ excluded RVH. Using this criterion, which has a $100 \%$ negative predictive value, with another criterion such as R:S V1 >1 or RV1 >6 with $100 \%$ positive predictive value narrows the group of patients with IPAH in whom the diagnosis of RVH needs further confirmation.

\section{Study Strengths and Limitations}

Our study has several strengths. Firstly, in contrast to previous historic reports we studied a homogeneous group of patients with IPAH. Secondly, we referred the ECG criteria directly to the RV mass or volume. Thirdly, we performed both ECG and CMR on the same day.

Our study has practical implications because we shown that of the 24 suggested ECG criteria for RVH only 10 may be useful for distinguishing patients with RVH in a group with IPAH and we established the best cut-off values for these criteria. Lastly, it is a novel finding of our study that only 1 criterion for RVH (ie, ventricular activation time in lead V1) correlates with RV dilation, which is a significant prognostic factor in IPAH. None of our patient had RV bundle branch block and all patients were in sinus rhythm, so it should be stressed that our observations are limited to patients in sinus rhythm and without bundle branch block.

The main limitation of this single-center study is the small group of patients, which results from the low prevalence of IPAH. It is possible that with a higher number of patients some of the correlations between RV characteristics and ECG criteria would appear statistically significant. However, in this comparative study different criteria were assessed in the same group of patients and the strongest associations were identified. Additionally, it should be noted that PAH is a rare disease and in the past autopsy studies in this field the numbers of cases were comparable to those in the present study. ${ }^{7}$ As previously mentioned, the current study evaluated only patients with IPAH to eliminate potential confounding factors for the ECG diagnosis of RVH, such as changed position of the heart within the chest because of hyperinflation of the lungs in pulmonary hypertension associated with chronic obstructive pulmonary disease or conduction abnormalities because of anatomical defects in pulmonary hypertension associated with congenital heart disease. Hence, our results cannot be extrapolated to patients with pulmonary hypertension secondary to other conditions and the predictive value of the ECG RVH criteria may vary according to the studied population. It is possible that other criteria are useful in other groups of patients. For example, deep $\mathrm{S}$ waves in the lateral precordial leads did not correlate with RV mass in our population, but are characteristic for RVH associated with chronic obstructive 
pulmonary disease. ${ }^{5}$

We are aware that the assessment of some of the proposed ECG criteria for RVH may be difficult or time-consuming. For example, it may be a challenge to diagnose the ventricular activation time in V1<0.01 s. However, the use of $50 \mathrm{~mm} / \mathrm{s}$ paper speed may help to overcome this problem. Additionally, it should be noted that such precise measurement of very short ECG intervals, although difficult, has been recommended by scientific societies; for example, the Joint European Society of Cardiology, American College of Cardiology, American Heart Association and World Heart Federation Task Force for the Redefinition of Myocardial Infarction, ${ }^{24}$ recommends the criterion $\geq 0.03 \mathrm{~s}$ for pathologic $\mathrm{Q}$ wave. We are also aware that some of the currently recommended ECG criteria for RVH, such as R:Sv5 to R:Sv1 or maxRv1,2+max $S_{1, a v L}-S_{v 1}$, may not be useful in clinical practice because of their complexity. However, as shown in Table 5, we propose other more simple criteria of similar accuracy for RVH diagnosis that are probably more feasible for use by practitioners.

\section{Conclusions}

In patients with IPAH, only the ECG voltage criteria based on $\mathrm{R}$ wave amplitude in V1 $\left(\mathrm{Rv} 1>6 \mathrm{~mm}, \mathrm{R}: \mathrm{Sv}_{1}>1, \mathrm{R}\right.$ : $\mathrm{Sv} 5$ to $\mathrm{R}: \mathrm{SV}_{1}<0.04, \operatorname{maxRv1,2}+\max \mathrm{SI}_{\mathrm{a}, \mathrm{al}}-\mathrm{Sv}_{\mathrm{v}}>6 \mathrm{~mm}, \mathrm{Rv}_{1}+\mathrm{SV}_{\mathrm{V}, 6}$ $>10.5 \mathrm{~mm}, \mathrm{R}: \mathrm{Sv} 1>\mathrm{R}: \mathrm{Sv} 3, \mathrm{R}: \mathrm{Sv} 1>\mathrm{R}: \mathrm{Sv} 4)$, R wave amplitude in aVR, $\mathrm{P}$ wave amplitude in II and ventricular activation time in V1 were useful for differentiating between patients with and without RVH. A ventricular activation time in V1<0.01 s excludes RVH, whereas Rv1 $>6 \mathrm{~mm}$, R:Sv1 $>1$, RaVR $>4 \mathrm{~mm}$, $\mathrm{R}: \mathrm{S} v 5$ to R:SV1 $<0.04$ and $\mathrm{P}_{\mathrm{II}}>2.5 \mathrm{~mm}$ confirm the diagnosis of $\mathrm{RVH}$ with $100 \%$ positive predictive value. In patients who do not fulfill these criteria the proposed cut-off points of other criteria with the highest sensitivity and specificity for the diagnosis of RVH can be used. Dilation of the RV can be diagnosed when the ventricular activation time is more than $0.045 \mathrm{~s}$.

\section{Acknowledgments}

This research was supported by the Polish Ministry of Science and Higher Education.

\section{Disclosures}

Source of Funding: This research was supported by the Polish Ministry of Science and Higher Education.

\section{References}

1. van Wolferen SA, Marcus JT, Boonstra A, Marques KM, Bronzwaer JG, Spreeuwenberg MD, et al. Prognostic value of right ventricular mass, volume, and function in idiopathic pulmonary arterial hypertension. Eur Heart J 2007; 28: 1250-1257.

2. Hagger D, Condliffe R, Woodhouse N, Elliot CA, Armstrong IJ, Davies C, et al. Ventricular mass index correlates with pulmonary artery pressure and predicts survival in suspected systemic sclerosisassociated pulmonary arterial hypertension. Rheumatology 2009; 48: $1137-1142$.

3. McLure LE, Peacock AJ. Cardiac magnetic resonance imaging for the assessment of the heart and pulmonary circulation in pulmonary hypertension. Eur Resp J 2009; 33: 1454-1466.

4. Hudsmith LE, Petersen SE, Francis JM, Robson MD, Neubauer S. Normal human left and right ventricular and left atrial dimensions using steady state free precession magnetic resonance imaging. $J$ Cardiovasc Magn Res 2005; 7: 775-782.

5. Hancock EW, Deal BJ, Mirvis DM, Okin P, Kligfield P, Gettes LS, et al; American Heart Association Electrocardiography and Arrhyth- mias Committee, Council on Clinical Cardiology; American College of Cardiology Foundation; Heart Rhythm Society. AHA/ACCF/HRS recommendations for the standardization and interpretation of the electrocardiogram: Part V: Electrocardiogram changes associated with cardiac chamber hypertrophy: A scientific statement from the American Heart Association Electrocardiography and Arrhythmias Committee, Council on Clinical Cardiology; the American College of Cardiology Foundation; and the Heart Rhythm Society: Endorsed by the International Society for Computerized Electrocardiology. Circulation 2009; 119: e251-e261.

6. Lehtonen J, Sutinen S, Ikaheimo M, Paakko P. Electrocardiographic criteria for the diagnosis of right ventricular hypertrophy verified at autopsy. Chest 1988; 93: 839-842.

7. Walker IC Jr, Helm RA, Scott RC. Right ventricular hypertrophy. I: Correlation of isolated right ventricular hypertrophy at autopsy with the electrocardiographic findings. Circulation 1955; 11: 215-222.

8. Guidelines for the diagnosis and treatment of pulmonary hypertension: The Task Force for the Diagnosis and Treatment of Pulmonary Hypertension of the European Society of Cardiology (ESC) and the European Respiratory Society (ERS), endorsed by the International Society of Heart and Lung Transplantation (ISHLT). Eur Heart $J$ 2009; 30: $2493-2537$.

9. Larose E, Ganz P, Reynolds HG, Dorbala S, Di Carli MF, Brown $\mathrm{KA}$, et al. Right ventricular dysfunction assessed by cardiovascular magnetic resonance imaging predicts poor prognosis late after myocardial infarction. J Am Coll Cardiol 2007; 49: 855-862.

10. Miszalski-Jamka T, Klimeczek P, Tomala M, Krupiński M, Zawadowski G, Noelting J, et al. Extent of RV dysfunction and myocardial infarction assessed by CMR are independent outcome predictors early after STEMI treated with primary angioplasty. JACC Cardiovasc Imaging 2010; 3: 1237-1246.

11. Kang KW, Chang HJ, Kim YJ, Choi BW, Lee HS, Yang WI, et al. Cardiac magnetic resonance imaging-derived pulmonary artery distensibility index correlates with pulmonary artery stiffness and predicts functional capacity in patients with pulmonary arterial hypertension. Circ J 2011; 75: 2244-2251.

12. Shors SM, Fung CW, Francois CJ, Finn JP, Fieno DS. Accurate quantification of right ventricular mass at MR imaging by using cine true fast imaging with steady-state precession: Study in dogs. Radiology 2004; 230: $383-388$.

13. Grothues F, Moon JC, Bellenger NG, Smith GS, Klein HU, Pennell DJ. Interstudy reproducibility of right ventricular volumes, function, and mass with cardiovascular magnetic resonance. Am Heart J 2004; 147: 218-223.

14. Bonderman D, Wexberg P, Martischnig AM, Heinzl H, Lang MB, Sadushi R, et al. A noninvasive algorithm to exclude pre-capillary pulmonary hypertension. Eur Resp J 2011; 37: 1096-1103.

15. Speich R. Diagnosing pulmonary hypertension: Is there a revival of the electrocardiogram? Eur Resp J 2011; 37: 994-996.

16. Kunishima T, Akashi YJ, Miyake F, Aoyama N, Kohshoh H, Yoshino $\mathrm{H}$, et al. The $\mathrm{T}$ wave inversion score is useful for evaluating the timecourse of acute pulmonary embolism. Circ J 2011; 75: 1222-1226.

17. Cowdery CD, Wagner GS, Starr JW, Rogers G, Greenfield JC Jr. New vector cardiographic criteria for diagnosing right ventricular hypertrophy in mitral stenosis: Comparison with electrocardiographic criteria. Circulation 1980; 62: 1026-1032.

18. Myers GB, Klein HA, Stofer BE. The electrocardiographic diagnosis of right ventricular hypertrophy. Am Heart J 1948; 35: 1-40.

19. Sokolow M, Lyon TP. The ventricular complex in right ventricular hypertrophy as obtained by unipolar precordial and limb leads. Am Heart J 1949; 38: 273-294.

20. Bove KE, Rowlands DT, Scott RC. Observations on the assessment of cardiac hypertrophy utilizing a chamber partition technique. Circulation 1966; 33: 558-568.

21. Antman EM, Green LH, Grossman W. Physiologic determinants of the electrocardiographic diagnosis of left ventricular hypertrophy. Circulation 1979; 60: 386-396.

22. Devereux RB, Phillips MC, Casale PN, Eisenberg RR, Kligfield P. Geometric determinants of electrocardiographic left ventricular hypertrophy. Circulation 1983; 67: 907-911.

23. Moore RB, Shapiro LM, Gibson DG. Relation between electrocardiographic repolarisation changes and mechanical events in left ventricular hypertrophy. Br Heart J 1984; 52: 516-523.

24. Thygesen K, Alpert JS, White HD; Joint ESC/ACCF/AHA/WHF Task Force for the Redefinition of Myocardial Infarction. Universal definition of myocardial infarction. Circulation 2007; 27: 26342653. 